\title{
Using Mobile Phones for Promoting Water Conservation
}

\author{
Rahuvaran Pathmanathan $^{1,2}$, Jon Pearce ${ }^{2}$, Jesper Kjeldskov ${ }^{1,2}$, Wally Smith ${ }^{2}$ \\ ${ }^{1}$ Aalborg University, Centre for Socio-Interactive Design, Denmark \\ ${ }^{2}$ The University of Melbourne, Australia \\ rahu@inwire.dk, j.pearce@unimelb.edu.au, jesper@cs.aau.dk,wsmith@unimelb.edu.au
}

\begin{abstract}
We report a design investigation that seeks to help people to conserve water in their homes through the use of mobile technology. To persuade people to use water more wisely, one approach is to give them tailored information about their water use and about other people's usage. Investigating this approach, a mobile application was implemented to explore the role of three different sources of information (weather, expert's advice and community information). Based on the evaluation, several themes for designing mobile technology for gardeners were identified. Findings from the study show that gardeners want more tailored messages from the system, and advice should come from more than one source of information, to have a greater opportunity to persuade.
\end{abstract}

\section{INTRODUCTION}

Water is precious and, as with many other countries in the world, Australia has for many years been through persistent drought and the effects of climate change. It is the driest inhabited continent in the world. The climate is highly variable across the continent as well as from year to year (Bureau of Meteorology, 2011). A consequence of this is that water restrictions are currently in place in many states and cities all over Australia. Depending on the location, there are restrictions on people watering their lawns, using sprinkler systems, hosing in paved areas, washing vehicles, and refilling spas and swimming pools. In the Melbourne metropolitan area, for example, the water storage was at its lowest for years in June 2009, at 25.6 percent (Melbourne Water, 2011) and led to very harsh water restrictions. At the time of writing, people are limited to water only on specified days, and some activities, such as washing cars or watering lawns, are prohibited.

With the restrictions in place, people became aware of when they were allowed to water their gardens, but there was and is still a lack of knowledge in the general community about how much water their plants need (Nansen et al., 2012). Some people tend to overwater their plants and let their watering systems run for a set amount of time. They tend to water within the restrictions even though their plants might not need it. The main issue here is the adaptability of knowledge presented.

Permission to make digital or hard copies of all or part of this work for personal or classroom use is granted without fee provided that copies are not made or distributed for profit or commercial advantage and that copies bear this notice and the full citation on the first page. To copy otherwise, to republish, to post on servers or to redistribute to lists, requires prior specific permission and/or a fee.

OZCHI '11, Nov 28 - Dec 2, 2011, Canberra, Australia

Copyright (C) 2011 ACM 978-1-4503-1090-1/11/11... \$10.00
People have different gardens with different plants, and the information given by the government is hard for the community to interpret and adapt to each personal garden practice. The project described in this paper addresses this challenge. The main goal is to explore the design of mobile technologies to help change people's behaviour and habits and reduce the amount of unnecessary water usage, with a view to collectively decreasing the water wastage throughout the Melbourne area. As a secondary effect, this might also result in more healthy and sustainable gardens.

The paper is structured as follows. First, we present related work done trying to make people more conscious about their use of water in private households. This includes an ongoing study around garden watering, as well as research carried out using mobile devices as a platform to change people's behaviour. We then present details on the process of designing, implementing and deploying a prototype mobile application using principles of persuasion to facilitate better water usage. Finally, findings from the analysis are presented and discussed by eliciting themes for designing technology to help people adapt information into their gardening practice.

\section{RELATED WORK}

Several studies about changing people's water-use in private households have been conducted (Arroyo et al., 2005; Kappel \& Grechenig, 2009; Kuznetsov \& Paulos, 2010; Pearce et al., 2008). Arroyo et al. (2005) present numerous persuasive techniques to increase awareness of water conservation in the domain of the sink, and created the WaterBot: a system that motivates people to turn off the tap when not using the water. Kappel et al. and Kuznetov et al. developed UpStream (Kappel \& Grechenig, 2009) and Show-Me (Kuznetsov \& Paulos, 2010 ) - both physical installations in the shower, which give information about their current water usage, with the goal of reducing their water usage. These studies showed that the developed technologies did change people's use of water.

Whilst the above techniques address the issues relating to water use within the home, Pearce and colleagues conducted a 4-year (2006-2010) and still ongoing study about developing and evaluating an online desktop application helping people water their gardens more efficiently (Pearce et al., 2008; Pearce et al., 2009). The first part of the study described a project design for an internet-based application to support gardeners' reasoning about the water demands and water supply for their gardens (Pearce et al., 2008). After the first study was conducted, an online-application, SmartGardenWatering, SGW, (smartgardenwatering.org.au) was developed in 
collaboration with horticultural scientists and interaction designers. A later study then described the investigation of how gardeners responded to advice from the software.

The SGW system takes the form a simulation in which where the gardener first defines various parameters for his/her garden and, based on the data, a profile of water demand for the garden is visualized. This comprises a watering schedule that shows the ideal frequency of when to water and the duration of watering required. The findings from a second study presented the types of factors that brought confidence or lack of trust in the visualized horticultural model and its application to a specific garden (Pearce et al., 2009). An issue raised in a later study was the disconnect between sitting at a desktop computer and exploring the horticultural issues in a technological context and actual garden practice (Pearce et al., 2010). This disconnect between being in the garden and at the desktop leads us to look at research carried out using other technology platforms - notably mobile devices - to persuade people to change their behaviour.

In the past 5 years, the functionality of mobile devices has gone through a drastic change from solely providing basic applications to more tailored and advanced programs. By looking at the present market for mobile applications, Apple's 'App Store' (currently the largest application store) shows the great demand for tailored applications in today's world (Apple, 2010).

The founder of Stanford Persuasive Technology Lab, B.J. Fogg, predicted a few years back that mobile devices would be the dominant platform for persuasion, mentioning that mobile platforms could motivate people to achieve their own personal goals (Fogg, 2003; Fogg, 2009). He saw the mobile phone as helping to succeed like a magic wand. He further commented: "Mobile technology can layer information into our moment-bymoment lives in a way that changes our behaviour". We therefore propose that the power of mobile persuasion can and will be used to enhance the quality of today's society by motivating people to use water more wisely and perhaps change their watering practice.

Furthermore, our mobile devices are able to gather and report current and localized information, which is relevant to us and our contextualized goals. For that reason, mobile devices have the potential to help motivate people more effectively than any other platform that they use in their daily life. According to Fogg (2003), drawing on previous psychology research, tailored applications have the tendency to be more effective than generic information in changing attitudes and behaviours (see also Jimison, 1997):

"Information provided by computing technology will be more persuasive if it is tailored to the individual's needs, interests, personality, usage context or other factors relevant to the individual" (Fogg, 2009).

Several projects have in various ways tried to persuade people with technology to become more conscious about reducing environmental impact (eco-feedback technology). Froehlich et al. conducted a comparative study of 89 environmental psychology papers and 44 papers from the HCI literature. The outcome of the study was a summary of key motivational techniques that HCIdesigners should be aware of to promote proenvironmental behaviour (Froehlich et al., 2010; Kappel \& Grechenig., 2009; Kuznetsov \& Paulos, 2010).

"Information must be easy to understand, trusted, attract attention and is remembered" (Brewer \& Stern, 2005)

Using information as a key motivation technique, Al Mahmud et al. (2008) conducted a study exploring the information given from three different visualization media (text, audio and video). The goal was to make people more conscious about their energy use in their home setting. They developed a mobile application called EZ Phone (Energy Zaving Phone) and conducted a pilot study in which they explored the three media's effectiveness in persuading users to conserve energy. The outcome from the study was that text was perceived to be most persuasive, and video was the least persuasive in changing people's behaviour to consider energy use.

A similar study by Roubroeks \& Ham (2009) explored given information about energy conservation through three different information-methods (text only, text+picture, text+video). They developed and tested a screen-based system. Findings from Roubroeks et al.'s study showed that the most effective way to persuade people in adapting their behaviour in a proposed direction was by using pictures to illustrate or expand on text.

The earlier research described above (Fogg, 2004; Roubroeks \& Ham, 2009; Froehlich et al., 2010; Brewer $\&$ Stern, 2005) suggests that information the gardeners need to support the goal of changing their environmental behaviour should be received on a mobile device, mediated as text with pictures. The information should be trustful and attract attention if it is to persuade people to change their behaviour. The rest of this paper presents the design, development and evaluation of an early prototype to explore how information given to persuade people on a mobile phone might change their environmental behaviour.

\section{RESEARCH DESIGN}

The study reported here explored three sources of information (scientific weather data, expert's advice, and community information) presented on a mobile device, and investigated each source's role in persuading people to adapt their behaviour in a proposed direction. These three sources of information were provided via a mobile web-application called Smart Garden Watering Advisor (SGW Advisor 2011). The prototype application was developed and deployed with 10 gardeners in Melbourne in a study over 5 weeks.

The participants were interviewed before and after they used the prototype over a period of 3 weeks. The pre-use interviews focused on exploring and understanding the participants' current garden knowledge and their use of IT-devices in their daily life. The pre-interview session was also used as an introduction to the mobile prototype. The prototype explored different ways of supporting gardeners with information, to make them become more 

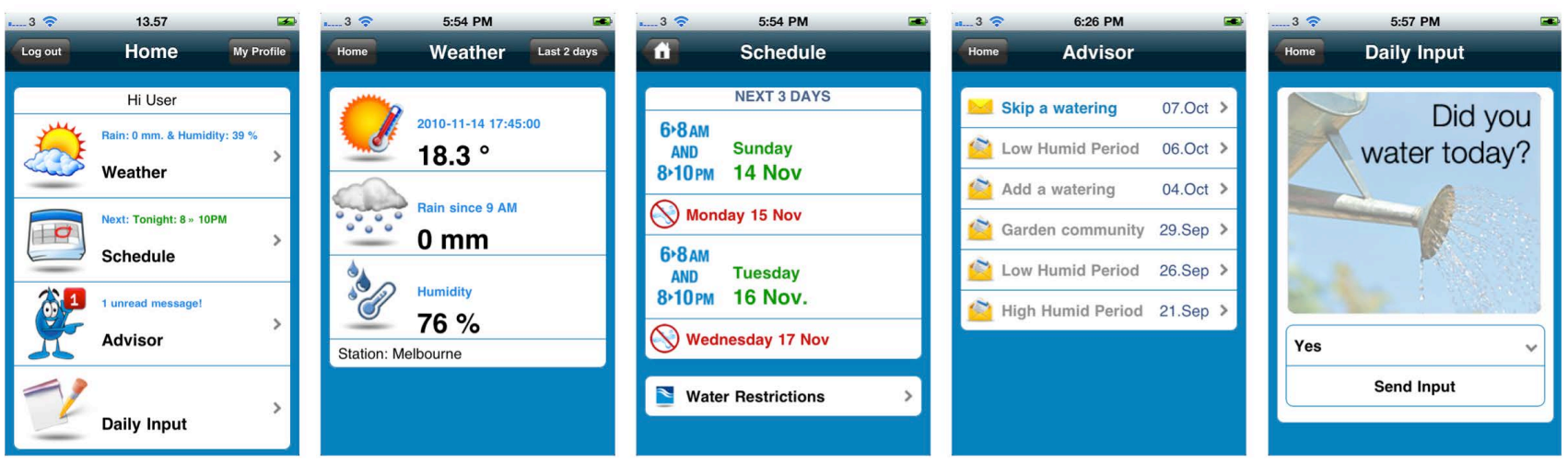

Figure 1. SGW Advisor showing the Home screen (left) and the four subsequent screens.

water-wise and change or correct their watering behaviour. The post-use interview focused on how the prototype facilitated information to the participants, and their reflections on the three different sources of information they had been introduced to during the 3 weeks study using the SGW Advisor

\section{THE SMART GARDEN WATERING ADVISOR}

The main goal of the Smart Garden Watering Advisor (SGW Advisor) was to explore whether gardeners found the mobile application supportive by giving them helpful information about their garden watering. We also explored what role the actual sources of information played in their decision to either water or skip a watering in their current watering schedule. We asked: Do the gardeners find the provided information trustful, and do they act on the given information?

One of our key intentions in the study was that the SGW Advisor system and its use should be as realistic as possible. Therefore, the weather information was given in real-time and localised to the nearest weather station. Even though the system presented in this paper can be seen as a technology prototype, our goal was to explore the role of the different sources of information played in advising the participants, rather than to explore technical or usability matters of the software itself.

\section{Design of the SGW Advisor prototype}

The SGW Advisor application is designed with a 'home screen' as its main window. The main window contains four menus items: Weather, Schedule, Advisor and Daily Input - see Figure 1.

\section{Weather menu}

The Weather menu provides information about the local weather for the weather station that the user lives closest to. It gives specific information about the current temperature, latest rainfall and humidity - see Figure 1. It also provides information about the last 2 days $\min / \mathrm{max}$ temperature, total rainfall, evaporation and average humidity.

\section{Schedule menu}

The Schedule menu gives information to the user about their current watering schedule for the next 3 days. The watering schedule is set initially by the user and in agreement with the actual water restrictions in the current state (Melbourne Water Restrictions, 2011).

Users are also provided with the information about the level of the current water restrictions and how these restrictions apply to the different watering methods (hand, manual or automatic watering).

\section{Advisor menu}

The Advisor menu shows an overview over the incoming messages from the system. The unread message(s) from the system are shown with an icon of an unopened envelope and read message(s) are shown as an opened envelope. By clicking on each message, the message opens and the reader is able to read the content of the message. This menu was the most important part of the system as the incoming messages allowed users to explore the three information sources.

\section{Daily Input menu}

The Daily Input menu is where the user is able to feed information into the system such as whether they have been watering the current day or not. The information is sent to a database, which is described in details in a later section.

\section{Three information sources}

The three different sources of information explored in this study were information about expert's choice, garden community and weather - see Figure 2.
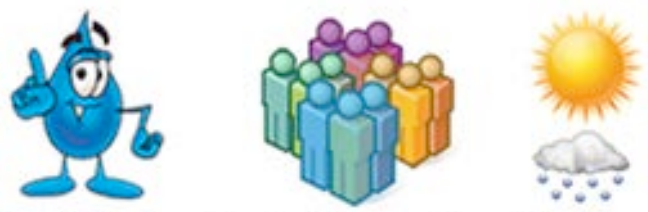

Expert's Choice Garden Community

Weather

Figure 2. Icons for the three information sources

\section{Expert's Choice}

The expert choice presented scientific weather data (Bureau of Meteorology, 2011), combined it with information from a knowledge database (SGW) and provided information in the inbox as to whether to skip, add or follow the regular watering schedule. The 
messages were sent to the participants from an animated water drop, named Watie (Figure 2).

\section{Garden Community}

This relates to the messages about what other gardeners are planning or already doing in their gardens. The information could be whether the majority of the community wanted to skip or add an extra watering to their regular watering schedule.

\section{Weather}

Messages received in the inbox were the scientific weather information from the Bureau of Meteorology (BoM). The information provided in the weather messages were objective and accurate information, in comparison to the other sources mentioned above. This message was provided to bring a diversity of information.

\section{The six incoming messages}

During the three weeks of the study, the participants received six different messages in the Advisor inbox from the three different sources. The six messages contained advice on whether to add an extra watering day or to skip a watering day compared to the current schedule. Every time a message was sent to the Advisor inbox, the participants also received a SMS on their mobile phone. Fogg conducted a healthcare study in which he mentioned that using SMS messages to notifying people, has a great potential to trigger them to a proposed behaviour (Fogg \& Allen, 2009). The three messages shown in Figure 3 are the messages that displayed only one information source in each message. These messages were from the weather, expert's choice and the garden community, respectively.
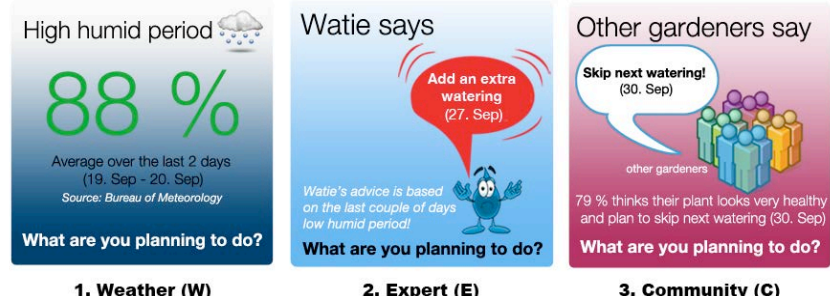

Figure 3. The three messages with only one source of information in each message

The final three messages users received were mixed messages, each with two different sources of information (Figure 4).

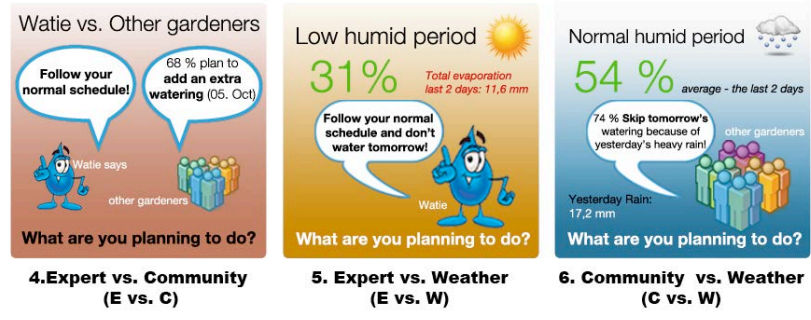

Figure 4. The final three messages, each with two different sources of information

For example, the fourth message the participants received (first image in Figure 4) was information about the expert advising about appropriate behaviour ('Follow your normal schedule'). However, the information from gardening community was in conflict with with the expert's choice and suggested adding an extra watering beyond the regular watering schedule (' $68 \%$ plan to add an extra watering').

\section{Technical Design}

The prototype software was implemented in 6 weeks by a single researcher (the first author). To avoid dependence on a single mobile platform (e.g. iPhone/Android application) the system was implemented as a mobile website. The mobile website was developed by using the open-source framework 'iWebkit' for iPhone mobile websites (iWebkit, 2011)

The system communicated with a PHP MySQL Server database in real-time, to ensure that actions from the users were logged by the system. The scientific weather information was obtained by running a script, extracting the data from the Bureau of Meteorology's website, and saved in the MySQL Server database. The SGW Advisor then extracted the weather information from the MySQL Server database and added the information to the users screen on the weather information page. When a user interacted with the SGW Advisor and entered information into the system, the data were saved in the MySQL Server database. This technical design is illustrated in Figure 5.

\section{USER STUDY}

The prototype was deployed in a study with 10 participating gardeners. The objective was to explore how the gardeners used the prototype, and their choice and preferences of the given messages from three different information sources.

\section{Participants}

The participating gardeners were recruited through a gardening course at Burnley Campus, University of Melbourne, and some through a Danish society, called Young Vikings, in Melbourne,.

Each participant had to meet a basic set of criteria to be selected for the study. They had to have a garden located in the greater Melbourne area. They were also required to have either a smartphone that allowed them to browse the Internet (Apple iPhone, HTC-mobile or BlackBerry) or a Google Chrome/Safari Internet browser on their personal computers. Furthermore, all the participants were required to have a mobile phone, which could receive SMS-messages for the notification about the incoming messages in the SGW Advisor.

The participants were asked to use the SGW Advisor at least once a day for the normal "Daily Input" data entry, which took approximately 2-3 minutes to do. Furthermore they were also asked to check their mobile phones for incoming SMS-messages, and to read and response to the received messages in the SGW Advisor Inbox during the study. The participants could use the SGW Advisor whenever they wanted to throughout the day.

Ten participants, 8 from the gardening course and 2 from Young Vikings, were chosen for the study. The participants had a spread of ages from 25 to 57 . The 
participants' garden knowledge varied, with 4 novices, 4 intermediate and 2 expert gardeners. Out of the 10 participants in the study, 5 had a smartphone that allowed them to browse the Internet, and the rest used a Chrome or Safari Internet browser on their personal computer.

\section{Method and data collection}

The initial meeting with each participant began with a quick tour of their garden was conducted, where the researcher and the participant had a chat about their garden and watering systems. The intention of this chat was to "break the ice" between the participant and the researcher. This was followed by a semi-structured interview to obtain a general understanding of people's garden knowledge and current gardening practice.

Among the questions asked were how they currently made use of any IT devices and how they obtained information about appropriate gardening practices. The interview lasted 20 minutes. A version of the SGW Advisor was introduced to the participant. The researcher went through the SGW Advisor with the participant, and the participant was free to ask questions about the case study. During this introduction, the participants received a manual that described the system step-by-step, to prevent any later problems during the case study.

The study was conducted during spring in the antipodes. However, the weather in Melbourne area varies considerably day by day during this season. The majority of the people living in the metropolitan area of Melbourne do not need to water their plants in this period. Hence, for the purpose of the research, a pea plant seedling in a pot was given to each participant - this provided a 'simulated' garden to take care of during the study.

Each participant was asked to look after their plant during the 3 weeks of case study; this required of watering it regularly (probably once a day but depending on conditions) and using the SGW Advisor to inform their decision as to whether to water or not. The use of the same pea plant across all participants controlled for other garden factors that might have influenced their behaviour. The participants were required to enter information every day into the SGW Advisor as to whether or not they had watered the plant.

The day before the actual case study began, the participants received a document with their regular watering schedule for the pea plant and descriptive information about the three information sources they would receive messages from during the study. During the study the SGW Advisor system was monitored remotely and any technical problems with the system were solved as quickly as possible. Every time a participant interacted with the system their input was saved in the database of the system.

After the three-week period, a second semi-structured interview was conducted with each participant. The purpose of this second interview was to discuss the different information sources that they received via the 6 incoming messages: what information sources they liked and disliked, and what messages they found most credible and useful. Participants were first asked questions reflecting their use of mobile devices as a supportive tool, followed by questions about how the three different sources of information were interpreted and used to reach watering decisions. Each of the 6 messages was discussed one by one. To remind the participants about the messages, small laminated cards displaying physical illustrations of each message were presented during the questioning. Finally, the possible benefits and drawbacks of the SGW Advisor system were discussed.

The system was tested on both smartphones and on personal computers with particular aims in mind. For the participants with smartphones, the system was tested to

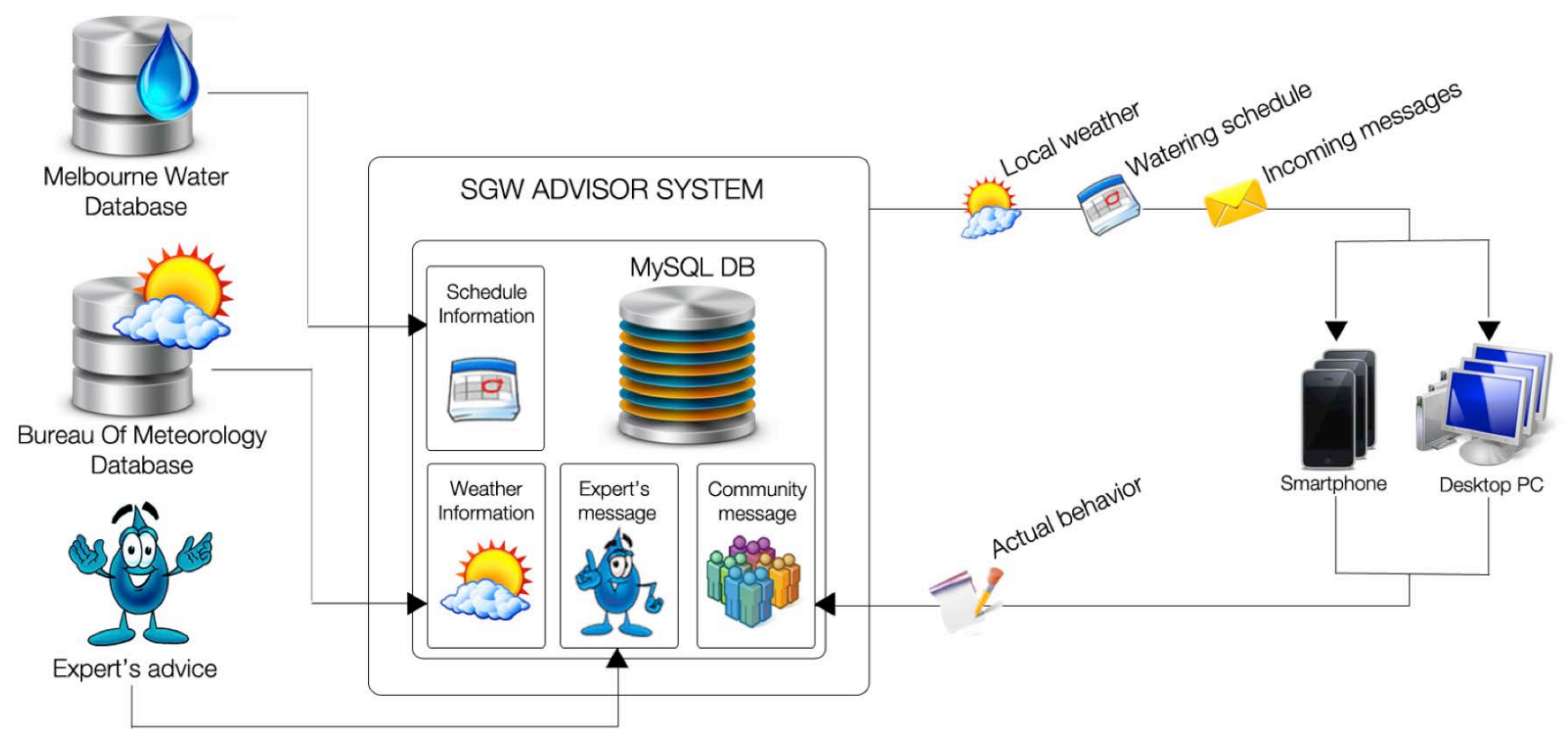

Figure 5. Structure of the system showing data sources (left), the SGW Advisor system (centre), and information flow (right). 
obtain reflections on the usage of the system on a mobile device and to see whether the participants found it persuading on this kind of device (Fogg, 2003). For the participants that used the system on a personal computer, the purpose was to obtain their reflections on using the system on a desktop and their thoughts about the disconnect between sitting at the desktop and doing the work in their garden (Pearce \& Murphy, 2010). The participants used the system almost every day and each participant remembered to respond on the 6 incoming messages.

\section{Data analysis}

Selected coding techniques from Grounded Theory (Strauss \& Corbin, 1990) were used to analyse the data. These were applied by the first author of this paper. Twenty audio recordings of 10 pre- and 10 post-interview responses were transcribed.

During this process, significant points made by participants were marked in the style of Open Coding. In total, 273 such significant elements were identified and subsequently categorized as 72 different phenomena. By using Axial Coding, connections between the different phenomena were made and formed into 12 categories, nine of which we discuss in the next section. These were then organised into four themes. Each of these themes is central in the analysis and is presented in the final 'Discussion' section.

\section{FINDINGS}

\section{Reactions to using the system}

One of the research questions was to explore whether gardeners found the mobile device supportive for their watering decisions. For this, the incoming 6 messages during the case study were used as a basis for discussion, focusing on whether they found the mobile device useful or not. The results from these discussions are described in this section, and discussed further in the 'Discussion' section.

\section{Actual vs. Preferred platform}

Out of the 10 participants in the study, 5 participants used the system on a mobile platform and the rest on a personal computer. The participants were asked to discuss the platform they used during the case study. Nine out of 10 participants preferred the system on a mobile device. One of the participants expressed:

"I found it very useful to have something in my hand and mobile. I could see it on my mobile, instead of looking it all up on my laptop. So you have the whole world in your hand - a gardener would always be outside, so I found it more useful for me."

Another participant who tried the system on his laptop said:

"I found it boring to do it on the computer. It would be more handy and mobile using the system on a phone than the computer."
The participants agreed that the preferred platform in the case study should be on a mobile platform rather than on a personal computer.

\section{Skip, Add or Both}

The question was discussed as to whether it was valuable to receive advisory information about when to add an extra watering or not. Nine out of 10 participants wanted the system to advise them on when to add an extra watering session if their plants needed water. A participant said that both notification methods were useful because:

"...even in summer you sometimes need to water an extra time, or skip a watering suddenly because of heavy rain."

If we look at the number of times the participants tended to add or skip a watering day according to the provided messages in the study, we see a progression in the three weeks of study. The number of skipped watering days increased from 4 in the first week to 9 in the last week of the study. Meanwhile, the number of added watering days decreased from 6 in the first week, to 2 in the last week of the study. The participants tend to skip more watering-days and added fewer watering-days - this was possibly because they learned to understand the messages better with time.

\section{Push vs Pull information}

The question of whether the participants wanted the information to be pushed to them, or they wanted to pull it from the system, was discussed. Nine out of 10 participants liked to be notified and reminded when there was a message in the system. The notification through SMS was for the majority of the participants a good method and triggered them go online and check their message. One participant expressed:

"SMS was very good, I really like the way it reminded me about to check my system for messages."

The SMS messages were good reminders for the participants to act and make decisions they possibly would not have been taken if the messages were not pushed to them.

\section{Automatic vs manual system}

The participants were asked about what type of watering system the SGW Advisor system would be more suitable for. The majority of the participants thought that the system would work best in gardens with manual watering systems rather than automatic watering systems because the gardeners would not have to make an effort each time they have to skip a watering:

"I think it would work best on a manual system than an automatic system because you don't need to switch the system on and off, and it could be problematic."

\section{Educational tool}

Eight out of 10 participants saw the system as an educational tool. One of the novice gardeners mentioned: 
"the application makes people more conscious and teaches them to have a better and more sustainable garden."

And another intermediate gardener expressed:

"Qualitatively, you try to teach and make people more conscious about the water use - and I like that I can see that the information that I read-makes me feel I am learning."

\section{Three sources of information}

In total, 6 messages were sent to the participants from three different information sources: BoM, Expert and Community. Here we discuss participants' responses to each of these areas.

\section{Weather Information}

All 10 participants found the information from the incoming messages about the weather conditions trustworthy. One of the participants in the case study expressed that:

"I found the weather information valuable and believable, because the weather was hot, and the information about a low humid period was real and trustworthy."

The majority of the participants rated the weather messages as very useful and they found the information given about humidity and rainfall realistic according to the weather throughout the case study. In the interviews a participant mentioned:

"Weather information is the most useful for me, because I assume that the weather information comes from the BOM."

The participants in the case study thus had great trust in the scientific weather information from the Bureau of Meteorology that led them to assess it as very useful information source. Though, some of the participants mentioned that the content of some messages they received were difficult to understand. A participant expressed:

"I haven't found out what high and low humidity means to the garden."

Another participant noted,

"I didn't understand the humidity information".

These misunderstandings of the humidity information in the weather messages will be discussed further in the next section.

\section{Expert's choice}

The messages with information from the expert had a more mixed impact on the participants. Only 7 out of 10 participants found it trustworthy. Some of the participants did not find the expert reliable. One participant noted:

"Expert's choice - my problem with him, is that I don't know him, and I don't know how he is finding the results. I am not sure, what to do with him."
And:

"This Watie guy looks like a little cartoon guy and for me not believable at all."

None of the participants complained about this information source, but they demanded more information about where the expert got his information from.

"He is a cute little character, but you might have to legitimize him".

Another participant expressed:

"Watie should have more information before I would find him more useful and I might be triggered to change my first decision because of the extra information"

However, not everyone questioned the expert's information source, and other participants expressed the following:

"The expert's choice was also okay for me. Because he is the expert, and he knows what's right, so I believed him." and "... I believed him - I took his advice, because I thought he was analysing the weather more than I do and gave me an advice - that I could use."

The majority of the participants found the information from the expert reinforcing what they were going to do, and in that case they found the information trustworthy:

"Expert's choice, that was fine. It kind of reinforced what I was going to do, anyway."

\section{Garden Community}

The information from the garden community was received as believable by the participants. Eight out of 10 found the information very believable and the majority found the information useful in helping to make decisions of what action they should take. One participant said:

"The gardeners had a bigger impact on me because they are gardeners and their decisions are very useful for me, so that's why I went ahead with their choice of skipping a watering."

Another participant expressed:

"I found those gardeners more believable in my decision whether to follow the advice or not ... I would always listen to people than a machine telling me something..."

However, a few participants expressed the view that not all information provided in the messages from the garden community were believable and one expressed:

"The garden community out there is already pretty bad, when I think about it. Think about all these people that don't have any clue what they are doing in their garden" and "I know that we as a population we way too much overwater our gardens."

Because of this lack of trust, their own decision had a bigger credibility than the received messages. Some suggestions were proposed:

"More tailored information from other gardeners with same type of plants - I would definitely find the 
information more believable and it might have changed my decision."

The lack of trust and the suggestions for more tailored information in the messages will be discussed in the next section.

\section{The three mixed messages}

The 4th, 5th and 6th message the participants received in the study were each a combination of two information sources. Participants found them very useful and to one of the messages a participant expressed:

"This message made me more comfortable about skipping the watering, by seeing information about what other people did, and the rainfall number."

The 6th message was also rated to be the most believable message and 9 out of 10 participants followed its advice and chose to skip a watering. These mixed information messages will be discussed further in next section.

\section{DISCUSSION}

Four interesting themes emerged from our analysis. Even though these themes were elicited from empirical data about gardeners, we suggest they may also be relevant to designing persuasive mobile technology in other domains where consumption of resources is critical. These themes relate to the participants' own judgements, misunderstanding messages, desires for tailored information, and the impact of mixed sources of information.

\section{Own Judgment}

While discussing the three different sources of information, 6 out of the 10 participants mentioned that their own judgment had the biggest impact when making any decisions whether to add, skip or keep following the normal schedule. It appeared that the three information sources were not determining decision outcomes, either individually or in any combination. Instead, some of the participants expressed that the messages they received only reinforced their own judgment of what to do.

What happened can be described as:

\section{Own judgment $\rightarrow$ Behaviour}

Where the desired result could be described as:

Own Judgment $+(w+e+c) \rightarrow$ New judgment $\rightarrow$ Behaviour

where $\mathrm{w}$, e and c refer to the weather, the expert and the community, respectively.

A study conducted by Nansen et al. also showed that the expert gardeners felt their intimate and detailed knowledge about water usage in their own gardens was always greater than any information that could be provided by a generic system (Nansen et al., 2012). This adds another challenging issue, to look more specifically at the different levels of gardeners, from novice to intermediate to expert. Different sources of information could be given to the different levels of gardeners; such as novice gardeners receiving information only from the garden community and the expert, where the garden experts received information only from the weather source (BoM).

\section{Misunderstanding of messages}

Some of the participants in the study found some of the messages received via the mobile device hard to understand. This would severely reduce the possibility for the information to persuade. Fogg (2003) addresses this as the Prominence-Interpretation Theory. He argues that to get a credibility assessment both prominence (the user is notified and understands the information) and interpretation (the user makes a judgment about it) has to happen (Fogg, 2003).

Therefore, the information provided to the user from the system has to be understandable such it can be interpreted and be able to persuade the user to make a judgment (Brewer \& Stern, 2005). Therefore, words like "low humidity" should be explained in further details so that the user understands what is meant.

\section{More tailored information}

The participants in the study wanted more tailored information in the messages they received, such as information about their water-usage and rainfall measures in their own garden. With more tailored information based on their own water-consumption and rainfall in their garden, they might have focussed more attention on the messages and hence process the information more deeply and be more likely to be persuaded by a plausible message.

This supports Fogg's theory about credibility. If the information is perceived as credible, it will have increased power to persuade. According to Fogg, credibility especially matters in HCI when systems like the SGW Advisor has to instruct or advice users, report measurements, or provide information and analysis (Fogg, 2003). Therefore, a focus on more information in the messages, such as contextualized weather information in suburbs and information about the smaller garden communities with similar plants in their neighbourhood, could be more relevant and persuasive to the user.

\section{Mixed sources of information - better impact}

Nine out of 10 participants expressed that they found the mixed messages - with information from more than one information source - very interesting. The ability to understand these mixed-source messages was considered to be greater. This suggests that the probability of perceiving the mixed message as credible support to making a new judgment was greater.

However, the use of too much information from different sources in a message sometimes lead to users feeling frustrated and failing to understand the message. It sometimes resulted in no decision being taken - or little influence of the information sources. It may therefore also be important to consider which type of gardener the message is sent to and how much information is needed to persuade. For instance, an expert gardener might need more facts, especially from different information sources to be convinced, where a novice gardener might be 
persuaded with a single message from one information source.

\section{CONCLUSIONS}

This paper has explored how to design mobile technology to persuade gardeners to use water more carefully. The design, implementation and deployment of a mobile application in the form of a prototype have been described, discussed and several themes have been elicited. Each of the ten gardeners in our study found the prototype to be a supportive tool to use in their gardening and perceived the three provided sources of information as useful in their watering practice. However, results indicate that gardeners tended to trust their own judgment on whether to water over and above the sources of information provided by the prototype.

A lack of trust in the information sources was shown and the gardeners demanded more personal, contextualized information to be able to regard the information sources as credible. The gardeners found the messages in the prototype that drew on mixed sources of information as most credible, and generally more information in the received message led to greater trust.

Although this was a limited study of just 10 participants, the results taken at face value suggest that a mobile device could serve to change gardeners' watering behaviour. It is hoped these themes will help fellow researchers when designing mobile technology with the aim of using information sources to persuade people's pro-environmental or resource-conserving behaviour. By pushing tailored information from mixed sources the participants in this study were more open to persuasion.

\section{FUTURE WORK}

As this study has revealed, there is a possibility to persuade people to be more conscious in reducing the amount of unnecessary water usage through using a mobile application as a supportive tool in their gardens. The indicative evidence from this study is currently being applied in a second investigation focusing on electricity usage. We will see whether the theories can be applied in this domain and whether there are any differences when persuade people's pro-environmental behaviour in use of electricity.

\section{ACKNOWLEDGMENTS}

The authors would like to thank the 10 participants in the case study for their time and interest.

\section{REFERENCES}

Al Mahmud, A., Mubin, O., Shahid, S., Juola, F.F., and de Ruyter B. EZ phone: persuading mobile users to conserve energy. Proc BCS-HCI'08, 7-10. (2008).

Anderson, R.E. Social impacts of computing: Codes of professional ethics. Social Science Computing Review 10, 2 (1992), 453-469.

Apple News Statement, September 2010 http://www.apple.com/pr/library/2010/09/09statement. html.
Arroyo, E., Bonanni, L. \& Selker, T., 2005. Waterbot: exploring feedback and persuasive techniques at the sink. In Proc. CHI 2005 ACM, pp. 631-639.

Australian Government - Bureau of Meteorology http://www.bom.gov.au/vic.

Brewer, G and Stern, P. (Eds), 2005. Decision Making for the Environment: Social and behavioural science research priorities, CHDCG, National Research Council.

Fogg, B.J. \& Allen, E., 2009. 10 Uses of Texting To Improve Health. In Proc. Persuasive, 2009.

Fogg, B.J., 2003. Persuasive Technology: Using Computers to Change What We Think and Do (Morgan Kaufmann Series in Interactive Technologies).

Fogg, B.J., 2003. Prominence-Interpretation Theory: Explaining How People Assess Credibility Online. New Horizons, p.722-723.

Fogg, B.J., 2009. The Behaviour Grid: 35 ways behaviour can change. In Proc. Persuasive 2009 ACM.

Froehlich, J., Findlater, L. \& Landay, J., 2010. The design of eco-feedback technology. In Proc. CHI 10, p.1999.

H. B. Jimison. Patient-specific interfaces to health and decision-making information, in Street, R., Gold, W. \& Manning, T., 1997. Health promotion and interactive technology: Theoretical applications and future directions.

iWebkit Mobile Framework http://iwebkit.net.

Kappel, K. \& Grechenig, T., 2009. Show-me: water consumption at a glance to promote water conservation in the shower. Proc. Persuasive 2009. ACM, pp. 1-6.

Kuznetsov, S. \& Paulos, E., 2010. UpStream : Motivating Water Conservation with Low-Cost Water Flow Sensing and Persuasive Displays. Audio, p.1851-1860.

Melbourne Water Restrictions http://www.target155.vic.gov.au/water-restrictions.

Nansen, B., Smith, W. and Pearce, J.M., 2012. Gardening Online: A Tale of Suburban Informatics. MIT Press.

Pearce, J., Murphy, J. \& Smith, W., 2008. Supporting gardeners to plan domestic watering: a case study of designing an 'everyday simulation'. In Proc. OzChi 2008, p.1-5.

Pearce, J.M. \& Murphy, B. 2010. Living on the hedge: SmartWatering in the community. Working paper: http://disweb.dis.unimelb.edu.au/staff/jonmp/pubs/Unp ublished\%202010/Living\%20on\%20the\%20hedge.pdf

Pearce, J.M., Smith, W., Nansen, B. and Murphy, J. 2009. SmartGardenWatering: experiences of using a garden watering simulation. In Proc. OzCHI. ACM, p. 217224.

Roubroeks, M. \& Ham, J., 2009. Does It Make a Difference Who Tells You What To Do? Exploring the Effect of Social Agency on Psychological Reactance. In D. Lockton et al., eds. In Proc. Persuasive 2009

Smart Garden Watering Advisor. 2011. http://www.sgwadvisor.com - also available through 
Apple's App store: http://itunes.apple.com/us/app/sgwadvisor/id439544541?mt=8\&ls=1

\section{SmartGardenWatering:} http://www.smartgardenwatering.com.au

Strauss, A. \& Corbin, J.M., 1990. Basics of Qualitative Research, SAGE
Swanston, P., 2001. Water: The Drop of Life (Northword Press).

Weekly Water Report - 19.06.2009

http://www.melbournewater.com.au 